Article

\title{
Fe-6.5 wt\%Si Powder Cores with Low Core Loss by Optimizing Particle Size Distribution
}

\author{
JianJun Huang ${ }^{1,2}$, Lixin Jiao ${ }^{3}$, Yu Yang ${ }^{3}$, Yaqiang Dong $1,4, * \mathbb{D}$, Yiqun Zhang ${ }^{1}$, Liang Chang ${ }^{1}$, \\ Mengji Gong ${ }^{1}$, Jiawei $\mathrm{Li}^{1,4}{ }^{1}$, Aina $\mathrm{He}^{1,4}{ }^{10}$ and Xinmin Wang ${ }^{1}$ \\ 1 Zhejiang Province Key Laboratory of Magnetic Materials and Application Technology, \\ CAS Key Laboratory of Magnetic Materials and Devices, Ningbo Institute of Materials Technology \& \\ Engineering, Chinese Academy of Sciences, Ningbo 315201, China; huangjianjun@nimte.ac.cn (J.H.); \\ zhangyiqun29@163.com (Y.Z.); changliang@nimte.ac.cn (L.C.); gongmengji@nimte.ac.cn (M.G.); \\ lijiawei@nimte.ac.cn (J.L.); heaina@nimte.ac.cn (A.H.); wangxinmin@nimte.ac.cn (X.W.) \\ 2 Nano Science and Technology Institute, University of Science and Technology of China, Hefei 230026, China \\ 3 Baowu Environmental Technology Wuhan Metal Resources Co., Ltd., Wuhan 430000, China; \\ E12444@baosteel.com (L.J.); 13163240985@163.com (Y.Y.) \\ 4 College of Materials Science and Opto-Electronic Technology, University of Chinese Academy of Sciences, \\ Beijing 100049, China \\ * Correspondence: dongyq@nimte.ac.cn; Tel.: +86-574-87617212
}

Received: 22 November 2020; Accepted: 16 December 2020; Published: 21 December 2020

\begin{abstract}
The effect of different particle size distribution of Fe- $6.5 \mathrm{wt} \% \mathrm{Si}$ powder on the microstructure and soft magnetic properties of the corresponding soft magnetic powder cores (SMPCs) was investigated. By optimizing particle size distribution, the density of SMPCs increased and the total core loss significantly decreased. According to the result of loss separation, density of SMPCs is inversely proportional to hysteresis loss, while with increasing the content of the fine particles, the eddy current loss significantly decreased. It was found that with magnetic powder of particle size-grading as $10 \%, 10 \%, 60 \%$, and $20 \%$ for particles with size between -75 to $+38,-38$ to $+23,-23$ to +13 , and $-13 \mu \mathrm{m}$, respectively, the Fe- $6.5 \mathrm{wt} \% \mathrm{Si}$ SMPCs exhibit optimal comprehensive magnetic performances with the effective permeability of about 60 , the percent permeability at 100 Oe is up to $70 \%$, and the lowest core loss of $553 \mathrm{~mW} / \mathrm{cm}^{3}$.
\end{abstract}

Keywords: soft magnetic composites; phosphating; core loss; particle size distribution

\section{Introduction}

Representing a specific category of magnetic materials, soft magnetic powder cores (SMPCs) consisting of metallic magnetic particles, insulating layer, and binder have been found a wide utilization of energy, information, transportation, and defense [1-4]. There are several distinct advantages of SMPCs compared with ferrite soft magnetic materials such as high saturation magnetization, high resistivity, and low magnetic anisotropy, which make SMPCs more suitable for the miniaturization and integration of power electronic devices, thus are widely used as inductors, filters, chokes, and transformers.

Compared with other SMPCs, Fe-6.5 wt $\%$ Si SMPCs have several significant advantages such as abundantly available raw materials, competitive prices, and outstanding comprehensive performances, which are especially suitable for the current technical requirements of low voltage, high current, high power density, and high frequency. Quite evidently, Fe-6.5 wt\%Si SMPCs have a great commercial application prospect in power and electronic industry. However, compared with FeSiAl, FeNi, and FeNiMo SMPCs, the core loss $\left(P_{\mathrm{cv}}\right)$ of Fe- $6.5 \mathrm{wt} \% \mathrm{Si}$ SMPCs is higher due to high coercivity of 
FeSi alloy. This problem restricts the wide application of Fe- $6.5 \mathrm{wt} \% \mathrm{Si}$ SMPCs. To date, in order to reduce the $P_{\mathrm{cv}}$ of Fe- $6.5 \mathrm{wt} \% \mathrm{Si}$ SMPCs, researchers have done a lot of work on the construction of insulation layers, such as $\mathrm{SiO}_{2}, \mathrm{MnZnFe}_{2} \mathrm{O}_{4}$, and $\mathrm{Fe}_{2} \mathrm{SiO}_{4}$ [5-7]. The insulation coating methods have good effect on reducing the eddy current loss to SMPCs at high frequencies. However, related electronic devices using Fe-6.5 wt\%Si SMPCs such as inductors and chokes, generally operates at low and medium frequency, where hysteresis loss became the dominant source of power losses. According to several previous studies, the hysteresis loss accounted for $70 \sim 90 \%$ of the power losses at $50 \mathrm{kHz}$ [8-10]. Meanwhile when the insulation layers became thicker, the hysteresis loss will be gradually increased due to the improvement of coercivity [11,12]. This means that the researches of innovative insulation layers have no significant effect on reducing the core loss at medium and low frequency. As a consequence, a simple and efficient method to reduce hysteresis loss at low frequencies and maintain other magnetic properties is an urgent problem to be solved.

The hysteresis loss strongly depends on the coercivity of the alloy and the density of SMPCs $[5,8,13]$. Several researchers have tried to reduce the coercivity of the Fe- $6.5 \mathrm{wt} \% \mathrm{Si}$ alloy by doping $\mathrm{Ti}$ and $\mathrm{Co}[14,15]$. Doping moderate specific elements may improve the internal microstructure of $\mathrm{Fe}-6.5 \mathrm{wt} \% \mathrm{Si}$ alloy to reduce the coercivity. In addition, some authors have attempted to increase density of SMPCs by increasing pressure or using different methods of compaction $[13,16,17]$. However, when the forming pressure reaches the marginal value, the magnetic performance of cores will not be obviously improved even if the pressure continues to increase. Therefore, some works on increment density by adjusting powder particles size distribution. It is demonstrated that the dimensions, purity, and size distribution of the magnetic particulate has tremendous influences on the microstructure and electromagnetic performance of the powder cores $[18,19]$. Some authors investigated the influence of the particle size of the powder on the core's magnetic properties [20,21]. Nevertheless, little attention has been devoted to the effect of particle size distribution on hysteresis loss, eddy current loss, and permeability of SMPCs. In this work, Fe-6.5 wt $\% \mathrm{Si}$ SMPCs with excellent comprehensive magnetic performance were prepared by particle size optimization engineering. Phosphate and epoxy resin were selected as the insulating layer and binder, respectively. The influences of the different particle size distribution of powders on the microstructure, hysteresis loss, eddy current loss, and permeability of SMPCs were investigated in details.

\section{Materials and Methods}

The gas-atomized Fe- $6.5 \mathrm{wt} \% \mathrm{Si}$ powder with the mean particle size of $55 \mu \mathrm{m}$ was supplied by Baowu Environmental Technology Wuhan Metal Resources Co., Ltd. (Wuhan, China) The epoxy resin (W-6C) was purchased from Sichuan Longhua Chenghua Adhesive Industry Co. Ltd. (Mianyang, China) All chemicals used were of analytical grade and were used as received without further purification.

The Fe- $6.5 \mathrm{wt} \%$ Si powder has been sieved into four size ranges, namely, -75 to $+38 \mu \mathrm{m}$ (group A), -38 to $+23 \mu \mathrm{m}$ (group B), -23 to $+13 \mu \mathrm{m}$ (group C), and $-13 \mu \mathrm{m}$ (group D). By uniform mixing these different particle sizes powders, four kinds of powder samples with different particle sizes were obtained. Figure 1 shows particle size distribution of five groups of powder samples. The Fe- $6.5 \mathrm{wt} \% \mathrm{Si}$ powders were put in orthophosphoric acid diluted in ethanol with a concentration of $0.012 \mathrm{~g} / \mathrm{mL}$ and stirred in the solution at $353 \mathrm{~K}$ until the ethanol solvent evaporated completely. The full phosphatization process lasted about $0.5 \mathrm{~h}$. After drying at $333 \mathrm{~K}$ in vacuum for $2 \mathrm{~h}$, the coated powders were mixed with $1.5 \mathrm{wt} \%$ epoxy resin as binder and $0.5 \mathrm{wt} \%$ zinc stearate as lubricate. The mixture was then compacted into toroidal cores (outer diameter $=20.3 \mathrm{~mm}$ and inner diameter $=12.7 \mathrm{~mm}$ ) at $1800 \mathrm{MPa}$. The compacted Fe- $6.5 \mathrm{wt} \%$ Si SMPCs were set into the tube furnace, annealed at $973 \mathrm{~K}$ for $1 \mathrm{~h}$, and cooled at room temperature for $1 \mathrm{~h}$ in vacuum.

The morphology of the composite powders was examined by scanning electron microscopy (SEM, ZEISS, Oberkochen, Germany) coupled with energy dispersive X-ray spectroscopy (EDS, ZEISS, Oberkochen, Germany). The phase identification and analysis of the coated powders was analyzed by X-ray diffraction (XRD, Siemens, Berlin, Germany) with $\mathrm{Cu}$ K radiation at a range of $2 \theta=30 \sim 90^{\circ}$ 
with a step size of $0.05^{\circ}$. Surface morphologies of the cross section of SMPCs and the raw and coated magnetic powders were observed by SEM. The effective permeability $\left(\mu_{\mathrm{e}}\right.$, Equation (1)) and quality factor of the SMPCs were measured by an impedance analyzer (Agilent 4294A) from $1 \mathrm{kHz}$ to $110 \mathrm{MHz}$ with the contact electrodes in two-terminal connection configuration under an excitation field of $1 \mathrm{~A} / \mathrm{m}$. The DC-bias performance with the maximum applied field of $100 \mathrm{Oe}$ was collected by a wide frequency LCR meter. The core loss was measured at the frequency ranging from 25 to $200 \mathrm{kHz}$ with the magnetic flux density of $100 \mathrm{mT}$ by an AC B-H curve analyzer (MATS-2010SA).

$$
\mu_{\mathrm{e}}=\frac{L_{S} l_{\mathrm{e}}}{\mu_{0} N^{2} A_{e}},
$$

where $L_{\mathrm{s}}, A_{\mathrm{e}}$, and $l_{\mathrm{e}}$ are the inductance, the cross-section area, and the mean flux density path length of the ring sample cores, respectively. $N$ is the coil turns. $\mu_{0}$ is the permeability of vacuum and the value is $4 \pi \times 10^{-7} \mathrm{H} / \mathrm{m}$.

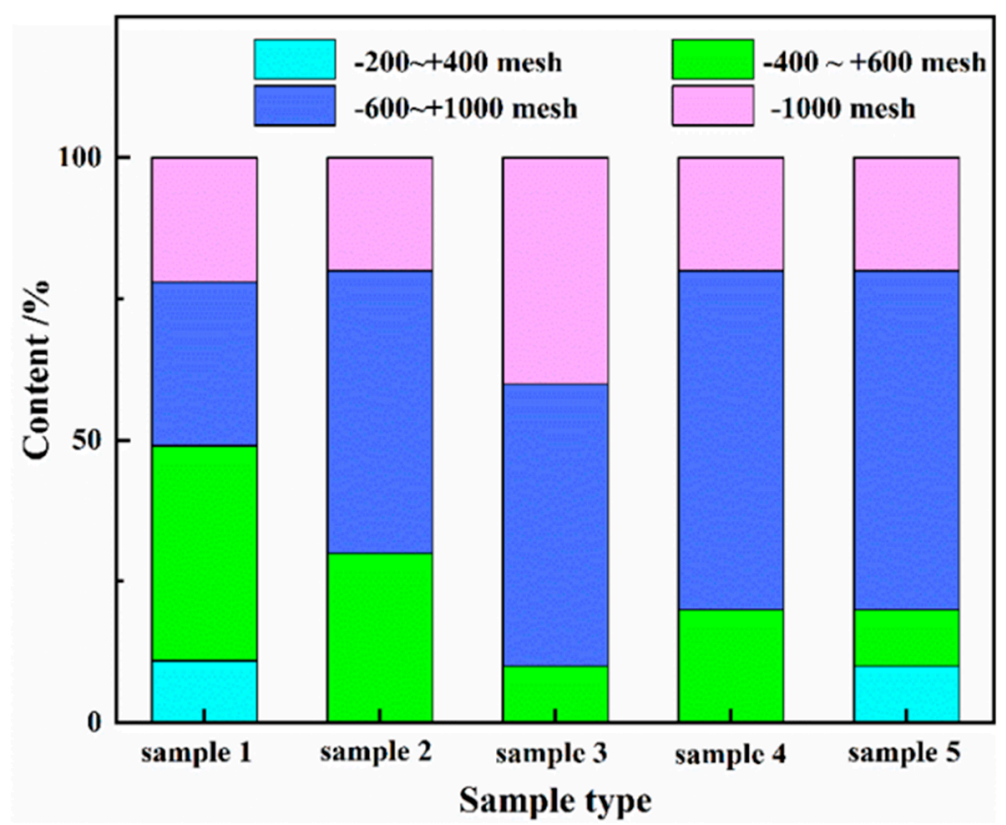

Figure 1. The particle size distribution of five groups of powder samples.

\section{Results}

\subsection{Microstructure of the Powders and Cores}

Figure 2 shows the SEM images and particle size distributions of Fe- $6.5 \mathrm{wt} \% \mathrm{Si}$ raw powders of groups A-D and the enlarged images of groups C-D. It can be seen that the sieved particles of each group have a relatively uniform size, and most of the particles exhibit spherical shape with smooth and clean surface. The spherical powders are easy to insulate compared with irregular shaped powders and can reduce the interparticle eddy current loss of the powder cores. According to the size distribution data, the $D_{50}$ of groups A-D are $54.18,47.32,24.42$, and $11.53 \mu \mathrm{m}$, respectively. The enlarged images of groups $\mathrm{C}-\mathrm{D}$ show that the smaller fine particles have very regular spherical shape, which is good for filling the gaps. The XRD patterns of Fe-6.5 wt \% Si raw powders and the insulated powders are shown in Figure 3. The peaks of Fe- $6.5 \mathrm{wt} \% \mathrm{Si}$ raw powders at about $44.3^{\circ}, 65.2^{\circ}$, and $82.4^{\circ}$ correspond to the (110), (200), and (211) crystal planes of bcc structure $\alpha$-Fe phase, respectively. The insulated powders including phosphate layer and epoxy resin also only exhibited the $\alpha$-Fe phase. As reported, this can be explained by two possible reasons. One is that the amount of the phosphate coating is too small to be detected by XRD. Another possible explanation is that the phosphate layer has an amorphous or nanocrystalline structure with the crystals smaller than $5 \mathrm{~nm}$ [22]. 

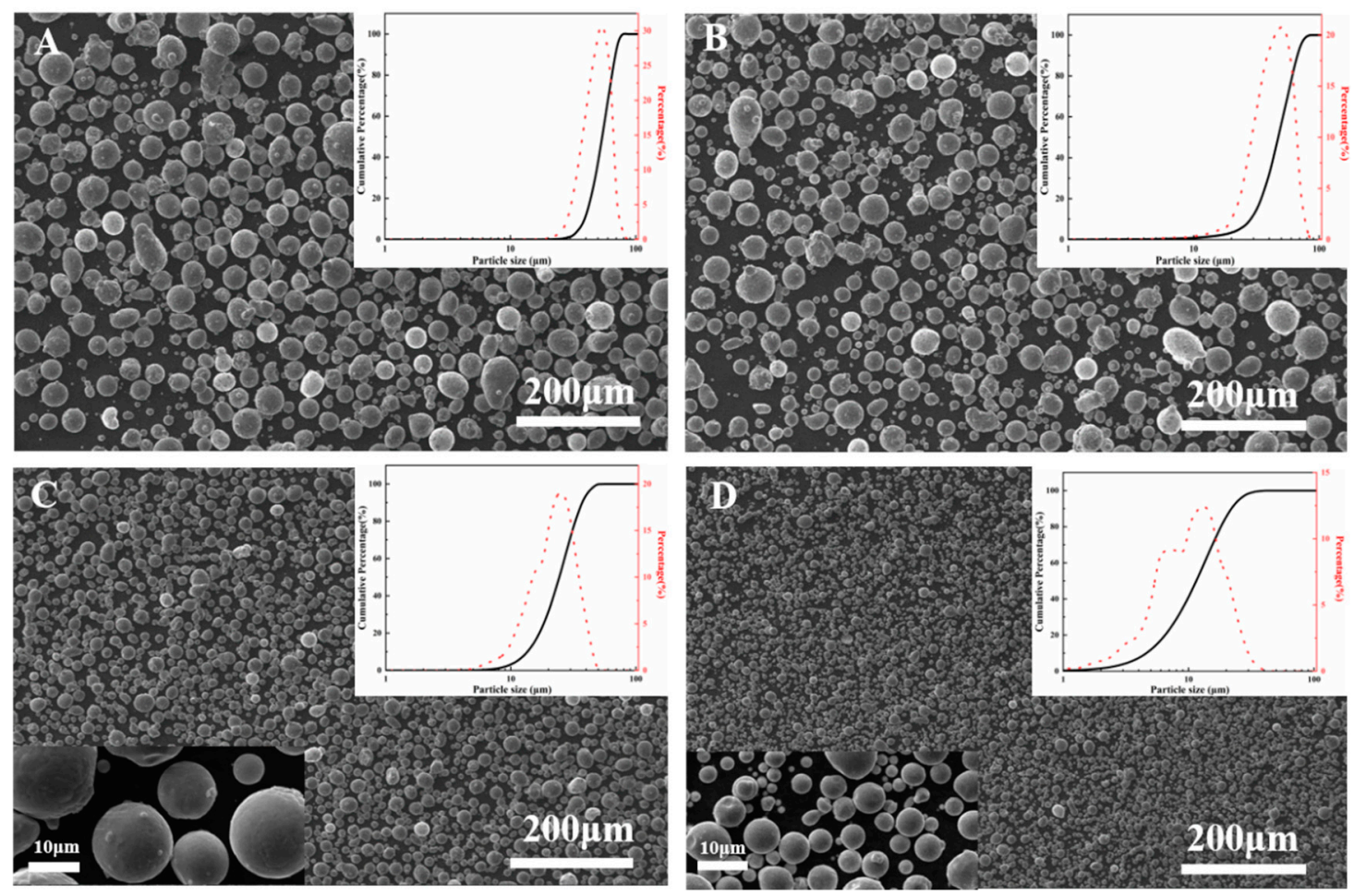

Figure 2. SEM images and particle size distributions of the Fe-6.5 $\mathrm{wt} \% \mathrm{Si}$ raw powders of (A) -75 to $+38 \mu \mathrm{m},(\mathbf{B})-38$ to $+23 \mu \mathrm{m},(\mathbf{C})-23$ to $+13 \mu \mathrm{m}$, and (D) $-13 \mu \mathrm{m}$. The insets are enlarged images of $\mathrm{C}$ and D.

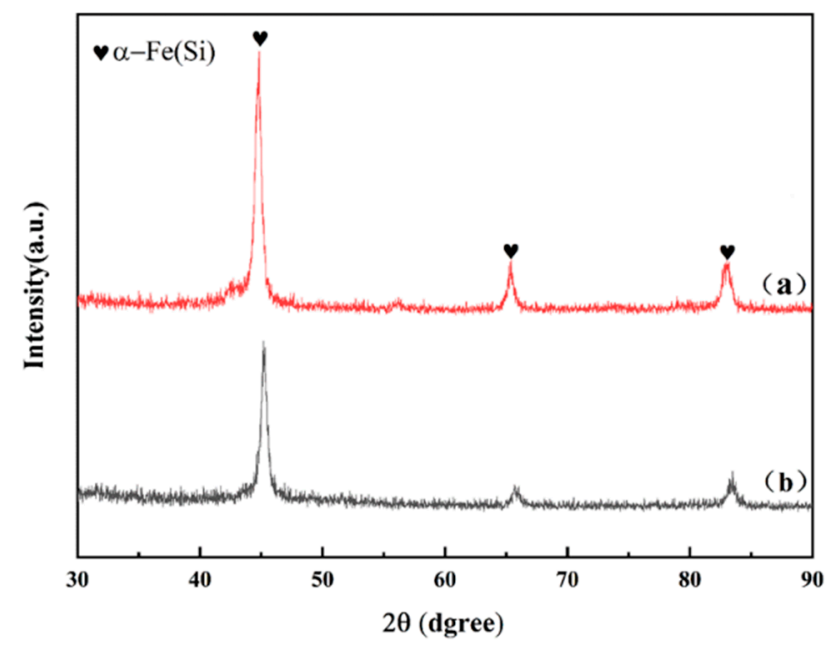

Figure 3. XRD pattern of (a) the raw Fe-6.5 wt \%Si powders and (b) the coated Fe-6.5\%Si powders.

In order to achieve excellent comprehensive magnetic properties of magnetic cores and considering economic applicability, we actually made multiple particle size distribution of magnetic cores, as shown in Figure 1. Finally, five typical SMPCs were prepared to analysis the microstructure and magnetic properties. Figure 4 shows the fracture morphology of Fe- $6.5 \mathrm{wt} \% \mathrm{Si}$ SMPCs with different particle size distribution. It can be seen that the microstructure of the cores is composed of different sizes of metal powder and air gaps, which form a tight network structure. According to Figure $4 \mathrm{a}$, the internal pores between Fe-6.5 wt\%Si powder with larger diameter are filled as the Fe-6.5 wt\%Si powder with smaller diameter, which leads to high density. In the light of Figure $4 b, c$, however, increase in the content of fine powder makes the fine powder agglomerated and creates more air gaps at the microlevel, and consequently, the density of SMPCs decreases from 6.4 to $6.2 \mathrm{~g} / \mathrm{cm}^{3}$. By changing the particle size 
distribution as $10 \%, 10 \%, 60 \%$, and $20 \%$ for particles groups of $\mathrm{A}-\mathrm{D}$, most of the internal pores are filled. Hence, the density of the Fe-6.5 wt\%Si SMPCs increases from 6.2 to $6.52 \mathrm{~g} / \mathrm{cm}^{3}$, as shown in Figure $4 \mathrm{f}$. Figure 5 shows the SEM image of the Fe- $6.5 \mathrm{wt} \% \mathrm{Si}$ powder after phosphating and the corresponding EDS spatial elemental mapping of the powders. The Fe- $6.5 \mathrm{wt} \% \mathrm{Si}$ powder surface was rough than the untreated powders and produced a flocculent phosphate coating. It was further confirmed by EDS that the surface of power formed uniform and continuous phosphate coating, which means that the phosphating layer is homogeneously coated on the surface of the Fe-6.5 wt\%Si powder. Compared with the thick and messy coating layer, the uniform and dense layer has smaller obstacle to the rotation of the magnetic domain, which is beneficial to reduce the hysteresis loss.
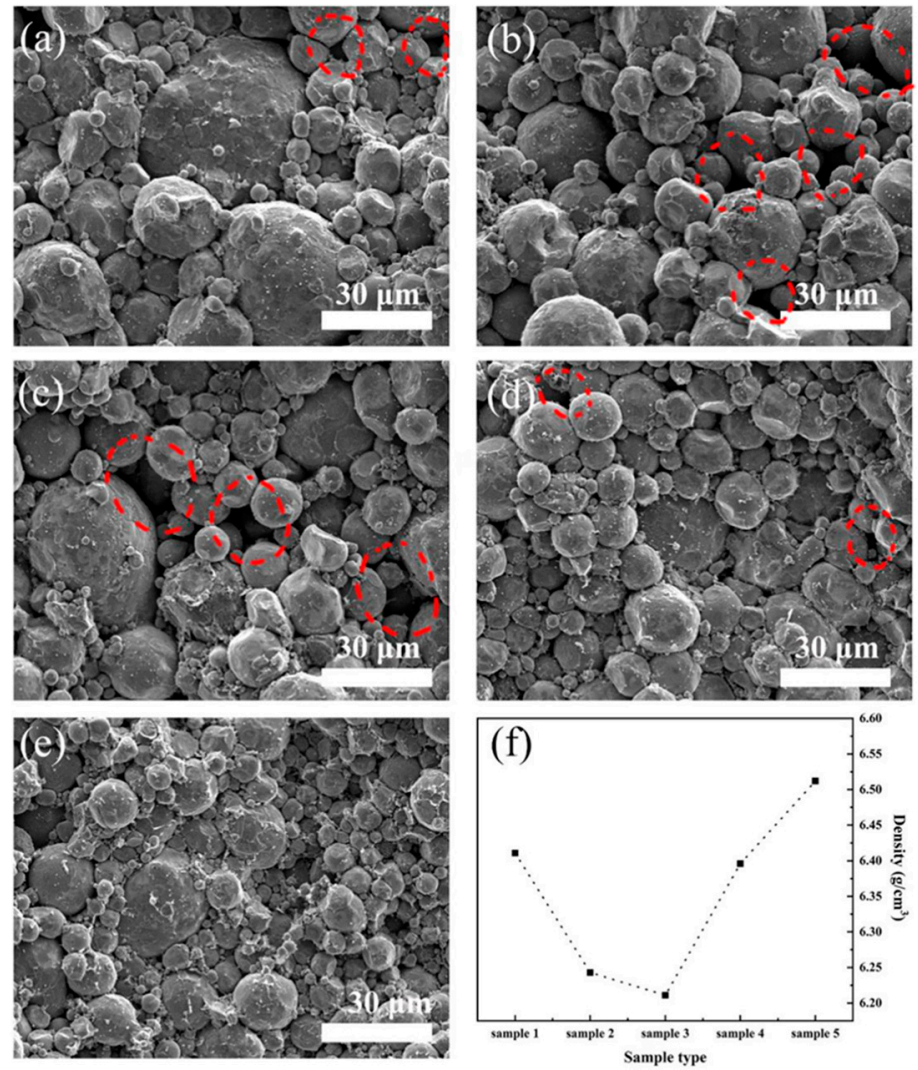

Figure 4. SEM images of fracture surface of the Fe-6.5 wt $\%$ Si SMCs with different particle size distribution, (a-e) represent sample 1, sample 2, sample 3, sample 4, and sample 5, respectively. In addition, (f) represents the density of $\mathrm{Fe}-6.5 \mathrm{wt} \% \mathrm{Si}$ powder cores for samples $1-5$.

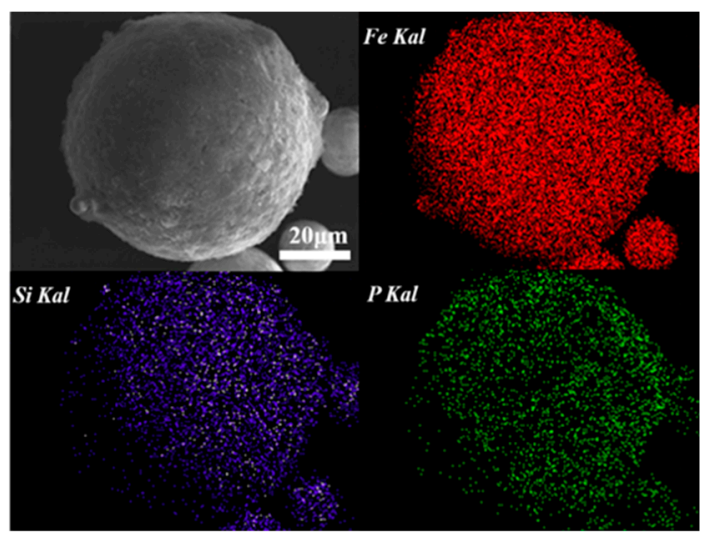

Figure 5. SEM micrograph and EDS elemental distribution maps of the coated Fe- $6.5 \mathrm{wt} \% \mathrm{Si}$ powders. 


\subsection{Magnetic Performance of the Fe-6.5 wt\%Si SMPCs}

It is commonly known that in the manufacturing process of soft magnetic composites, defects such as air gaps and holes will inevitably occur inside. It has been reported that a magnetic core is considered as a distributed air gap inductor with 10-10 8 air gaps/cm determined by the dimensions of the magnetic powder [23]. These defects will deteriorate the magnetic properties of SMPCs by hindering the domain wall displacement and domain rotation. The most effective way to reduce these defects is to increase the density of the powder cores. Figure $4 \mathrm{f}$ illustrates the density of the powder cores with different size distribution. Samples 2-4 removed group A and increased the content of group $\mathrm{C}$ compared to the raw powder. However, it does not help to increase density. This means that large particle powders are indispensable in high-density powder cores. Finally, we designed the particle size distribution of sample 5. After high pressure molded at $1800 \mathrm{MPa}$, sample 5 had relatively high density $\left(6.52 \mathrm{~g} / \mathrm{cm}^{3}\right)$ and this means less defects, which is the key to obtain high performance magnetic powder cores.

Figure 6a shows the effective permeability $\left(\mu_{\mathrm{e}}\right)$ as a function of the frequency for the Fe-6.5 wt $\% \mathrm{Si}$ SMPCs. All samples exhibited stable permeability at more than $1 \mathrm{MHz}$. The $\mu_{\mathrm{e}}$ for samples $1-3$ was positively correlated with density of the powder cores. The $\mu_{\mathrm{e}}$ of the magnetic core can be calculated by Equation (2) [24]:

$$
\mu_{\mathrm{e}}=\frac{\mu_{\mathrm{i}} m \rho^{\prime}+2 \mu_{\mathrm{i}} m^{\prime} \rho}{\mu_{\mathrm{i}} m \rho^{\prime}-\left(\mu_{\mathrm{i}}-3\right) m^{\prime} \rho},
$$

where $\mu_{\mathrm{i}}$ is the intrinsic permeability of the material, $m$ and $\rho$ are the mass and density of powder cores, $m^{\prime}$ and $\rho^{\prime}$ are the mass and density of magnetic powder, respectively. According to Equation (2), it is clear that the effective permeability is positively related to the density of the soft magnetic powder cores. This is consistent with the results of samples 1-3. However, the density of sample 4 was almost the same as that of sample 1, but the effective permeability differs by 5 . Meanwhile, sample 5 has a higher density, but the $\mu_{\mathrm{e}}$ is still lower than sample 1. This can be explained by Equation (3) of effective permeability [25]:

$$
\mu_{\mathrm{e}}=\frac{D \mu_{\mathrm{i}}}{D+\delta \mu_{\mathrm{i}}},
$$

where $\mu_{\mathrm{i}}$ is the intrinsic permeability of the material, $D$ is the particle size of the material powder, and $\delta$ is the length of the air gap between the powder particles. This equation described the particle size dependence of the effective permeability in SMPCs, and the particle size of the powder is obviously proportional to the effective permeability. In samples 4 and 5, the content of group $C$ increased compared with sample 1 , thus the average particle size was smaller, which has negative effect to effective permeability of SMPCs.

Figure $6 \mathrm{~b}$ depicts the variations in $P_{\mathrm{cv}}$ with the frequency at $100 \mathrm{mT}$ for the samples 1-5. The difference of $P_{\mathrm{cv}}$ at a relatively low frequency range $(25-75 \mathrm{kHz})$ is not obvious. However, along with the increase in testing frequency, the samples 3-5 clearly exhibit much lower core loss than sample 1. Sample 5 exhibited the lowest $P_{\mathrm{cv}}$ at the tested frequency in these samples, in which $P_{\mathrm{cv}}$ at $100 \mathrm{mT} / 50 \mathrm{kHz}$ dropped by $15.4 \%\left(553 \mathrm{~mW} / \mathrm{cm}^{3}\right)$ compared with sample $1\left(654 \mathrm{~mW} / \mathrm{cm}^{3}\right)$. The $P_{\mathrm{cv}}$ refers to various energy losses produced by magnetic materials in time-varying magnetic field, which mainly consists of hysteresis loss $\left(P_{\mathrm{h}}\right)$, eddy current loss $\left(P_{\mathrm{e}}\right)$, and residual loss $\left(P_{\mathrm{r}}\right)$. It is worth noting that the residual loss becomes an important part of the total loss only at very low or very high frequencies, which is generally ignored in SMPCs [26]. Therefore, the $P_{\mathrm{cv}}$ of the SMPCs can be expressed as follows:

$$
P_{\mathrm{cV}}=P_{\mathrm{h}}+P_{\mathrm{e}}
$$

Theoretically, the $P_{\mathrm{cv}}$ can be represented by the following equation $[27,28]$ :

$$
P_{\mathrm{cv}}=P_{\mathrm{h}}+P_{\mathrm{e}}=K_{\mathrm{h}} \times f+K_{\mathrm{e}} \times f^{2}
$$


where $K_{\mathrm{h}}$ is the hysteresis loss coefficient, $K_{\mathrm{e}}$ is the eddy current loss coefficient, and $f$ is the frequency. According to Equation (5), the hysteresis loss and the eddy current loss are proportional to frequency $(f)$ and the square of frequency $\left(f^{2}\right)$, respectively. This means that the core loss of soft magnetic composites is dominated by $P_{\mathrm{h}}$ at low frequency conditions and $P_{\mathrm{e}}$ dominates at high frequency conditions, which is consistent with the results of loss separation in Figure $6 \mathrm{c}, \mathrm{d}$.

The $P_{\mathrm{h}}$ is produced by the coercivity of the magnetic materials. Each time the magnet completes a cycle of the magnetization curve, the area within the curve is a measure of energy loss [23], which can be expressed as follows:

$$
P_{h}=f \oint H d B
$$

where $f$ is the frequency, $H$ represents the applied magnetic field intensity, and $B$ stands for the magnetic induction intensity. It is well established that $P_{\mathrm{h}}$ is mainly determined by the coercivity and density of the soft magnetic composite [8]. Furthermore, the coercivity is determined by intrinsic physical constants of magnetic powder such as the magnetostriction coefficient, magneto crystalline anisotropy, and grain size, while the purity of magnetic particles also affects the coercivity. In this work, the raw materials of all samples were the same batch of Fe- $6.5 \mathrm{wt} \%$ Si powder, thus their coercivity differs very little. This means that we can reduce the air gap and holes in the powder cores to decrease the $P_{\mathrm{h}}$ by increasing the density of the magnetic powder cores.

The $P_{\mathrm{e}}$ is the energy loss caused by the induced current in the conductor when an alternating magnetic field is applied to a magnetic material. The total eddy current loss of the SMPCs can be divided into the internal eddy current loss of microscopic particles and the eddy current loss between macroscopic particles [29]. The Pe sketchily scales as the operating frequency squared, and it can be depicted as follows [30,31]:

$$
P_{\mathrm{e}}=P_{\mathrm{e}}^{\text {inter }}+P_{\mathrm{e}}^{\text {intra }}=\frac{\left(\pi d_{\mathrm{eff}} B_{\mathrm{m}}\right)^{2}}{\beta \rho_{1}} f^{2}+\frac{\left(\pi d B_{\mathrm{m}}\right)^{2}}{20 \rho_{2}} f^{2},
$$

where $P_{\mathrm{e}}^{\text {inter }}$ is the interparticle eddy current loss; $P_{\mathrm{e}}^{\text {intra }}$ is the intraparticle eddy current loss; $d_{\mathrm{eff}}$ refers to the effective size of eddy current loss; $d$ is diameter of the magnetic powders; $B_{\mathrm{m}}$ represents the applied magnetic flux density; $\beta$ is the constant related to the geometry of the magnetic powder core; $\rho_{1}$ and $\rho_{2}$ are the electric resistivity of the SMPCs and magnetic powders, respectively; and $f$ is the magnetic field frequency. According to Equation (7), increasing the resistivity of magnetic powder and reducing the particle size are the effective ways to decrease the intraparticle eddy current loss. In addition, the key to reduce the interparticle eddy current loss is to increase the resistivity through insulation coating to block the eddy current in the magnetic particle.

Figure $6 \mathrm{c}$ shows the changes of the hysteresis loss with the frequency for the different particle size distribution of samples. The $P_{\mathrm{h}}$ of the five samples first increases and then decreases, which follows opposite trend with the change of the density. This may be explained by that the increasing of density is conducive to reduce air gaps and voids in the magnetic powder cores. Based on detailed data, the $P_{\mathrm{h}}$ of the five samples accounts for about $90 \%$ in the total core loss at $100 \mathrm{mT} / 50 \mathrm{kHz}$, consistent with the theoretical prediction. By adjusting the particle size distribution, the $P_{\mathrm{h}}$ of sample $5\left(509 \mathrm{~mW} / \mathrm{cm}^{3}\right)$ dropped by $9 \%$ compared with sample $1\left(560 \mathrm{~mW} / \mathrm{cm}^{3}\right)$ at $100 \mathrm{mT} / 50 \mathrm{kHz}$. Figure $6 \mathrm{~d}$ presents the changes of the eddy current loss with the frequency for the different particle size distribution of samples measured at $100 \mathrm{mT}$. With the increase in fine powder contents, the $P_{\mathrm{e}}$ of samples $2-5$ has obvious reduction, and difference increase when frequency increases. Specifically, The $P_{\mathrm{e}}$ of sample 5 $\left(44.2 \mathrm{~mW} / \mathrm{cm}^{3}\right)$ dropped by $53 \%$ compared with sample $1\left(94 \mathrm{~mW} / \mathrm{cm}^{3}\right)$ at $100 \mathrm{mT} / 50 \mathrm{kHz}$. Meanwhile sample 3 exhibits the lowest $P_{\mathrm{e}}$ due to minimum average particle size, and this matches the predicted result. The tremendous reduction in $P_{\mathrm{e}}$ makes us conclude that it is an effective method to reduce $P_{\mathrm{e}}$ by reducing the particle size of powder. 

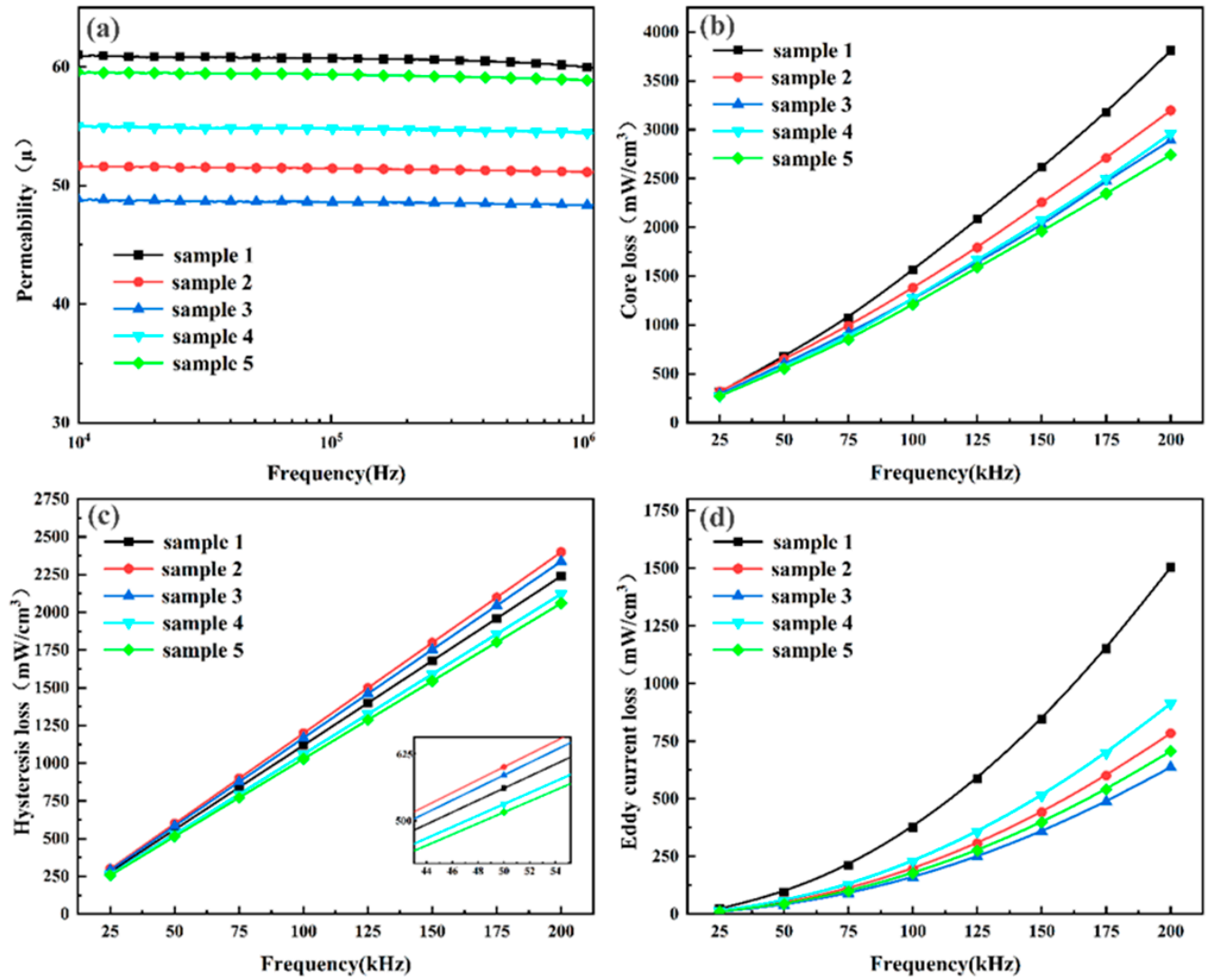

Figure 6. The effective permeability (a), the total core loss (b), hysteresis loss (c), and eddy current loss (d) as a function of the frequency for samples 1-5.

In physics and engineering, the quality factor $(Q)$ is a dimensionless parameter that describes the insufficient damping of the oscillator or resonator. Additionally, in SMPCs, the $Q$ is numerically the ratio of the real and imaginary parts of the complex permeability. Figure 7 shows $Q$ as a function of the frequency for Fe-6.5 wt\%Si SMPCs with different particle size distribution. The $Q$ values of the five samples follow similar trend (it first increases with the frequency and then decreases), the preponderance of the Fe- $6.5 \mathrm{wt} \% \mathrm{Si}$ SMPCs with optimized particle size distribution in terms of $Q$ is noticeable. Compared with the raw powder cores, the peak of $Q$ remarkably increased and shifted to higher frequencies for the samples which the particle size distribution was optimized. In detail, sample 5 exhibits the maximum $Q$ factor of 90.5 at a frequency of $213 \mathrm{kHz}$; it is significantly improved by $53 \%$ in contrast to sample 1 (59), which indicates lower core loss and superior soft magnetic properties at high frequency. The detailed data of soft magnetic properties in this work and the comparison with previous studies and the products of some companies are shown in Table 1. The Fe- $6.5 \mathrm{wt} \% \mathrm{Si}$ SMPCs with optimized particle size distribution fabricated in this study exhibit excellent comprehensive soft magnetic properties than those of the previously reported Fe- $6.5 \mathrm{wt} \% \mathrm{Si}$ SMPCs and some Fe-6.5 $w t \% S i$ SMPCs in the market. In particular, the Fe- $6.5 \mathrm{wt} \% \mathrm{Si}$ SMPCs have very low core losses while the effective permeability and DC-bias performance can be maintained; this may make Fe- $6.5 \mathrm{wt} \% \mathrm{Si}$ SMPCs with more application scenarios. 


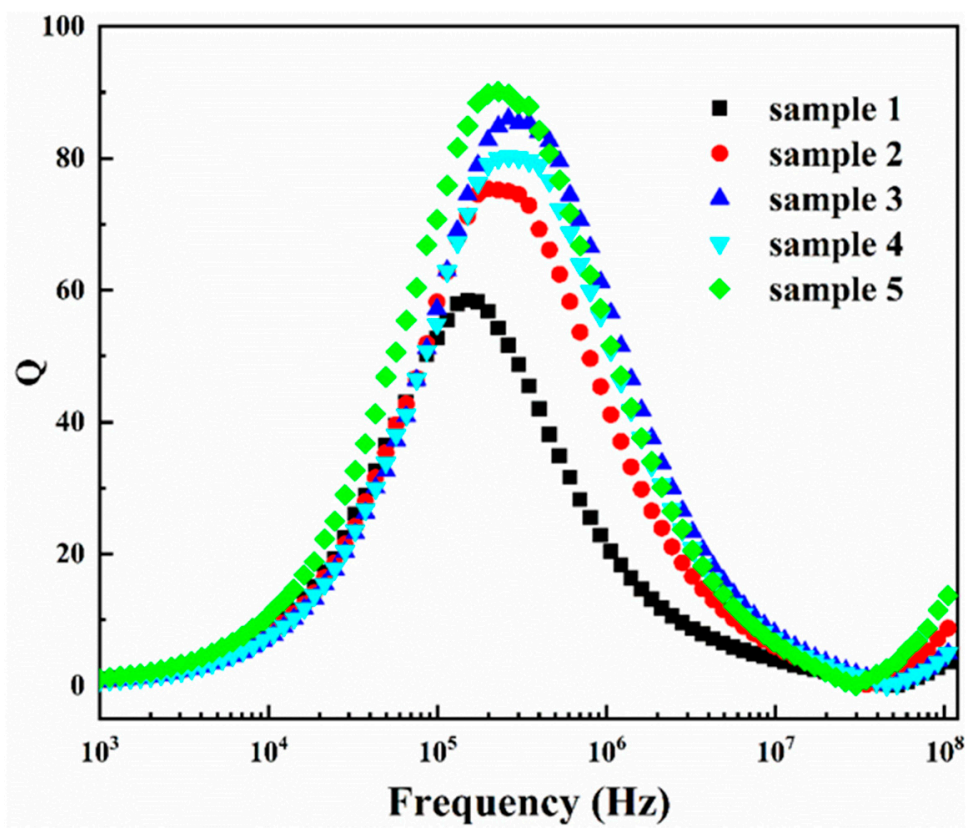

Figure 7. The quality factor as a function of the frequency for samples 1-5.

Table 1. Comparison of Fe-6.5 wt $\%$ Si soft magnetic powder cores (SMPCs) performance of literature reported previously, products of some companies and this work.

\begin{tabular}{|c|c|c|c|c|}
\hline Samples & Density $\left(\mathrm{g} / \mathrm{cm}^{3}\right)$ & $\mu_{\mathrm{e}} @ 100 \mathrm{kHz}$ & DC-Bias@100 Oe & $\begin{array}{l}\text { Core Loss * } \\
\left(\mathrm{mW} / \mathrm{cm}^{3}\right)\end{array}$ \\
\hline $\mathrm{Fe}-6.5 \% \mathrm{Si}[15]$ & 6.918 & 103.36 & - & 781.03 \\
\hline $\mathrm{Fe}-6.5 \% \mathrm{Si}[14]$ & 5.91 & 52.9 & $56 \%$ & - \\
\hline $\mathrm{Fe}-6.5 \% \mathrm{Si}[8]$ & $5.28-6.01$ & $57.2-75.6$ & - & $1015.2-1446.8$ \\
\hline $\mathrm{Fe}-6.5 \% \mathrm{Si}[32]$ & 6.88 & 112.13 & - & 500 \\
\hline $\operatorname{CSC}^{* *}$ & - & 60 & $73 \%$ & 700 \\
\hline MAGNETICS ** & - & 60 & $70 \%$ & 680 \\
\hline Sample 5 & 6.512 & 60 & $70 \%$ & 553 \\
\hline
\end{tabular}

* measured at $100 \mathrm{mT} / 50 \mathrm{kHz}$; ${ }^{* *}$ Data from official websites.

\section{Conclusions}

The Fe-6.5 wt\%Si powder cores with five particle size distribution have been fabricated via inorganic-organic hybrid coating. The influence of the different particle size distribution of the Fe-6.5 wt\%Si powder on the SMPCs' magnetic properties was discussed. It was found that the comprehensive magnetic properties can be optimized by adjusting the particle size distribution of the powder. Sample 5 exhibits best comprehensive magnetic properties, i.e., the $\mu_{\mathrm{e}}=60(1 \mathrm{MHz})$, $P_{\mathrm{cv}}=553 \mathrm{~mW} / \mathrm{cm}^{3}$ measured at $100 \mathrm{mT} / 50 \mathrm{kHz}$, and DC-bias performance is $70 \%$ at 100 Oe. In this work, we adopted a simple and efficient method to prepare magnetic powder core with excellent comprehensive magnetic performance, which is helpful for plans to manufacture high-performance magnetic powder cores.

Author Contributions: Conceptualization, J.H., Y.Z., and Y.D.; methodology, J.H., L.C., and M.G.; resources, L.J. and Y.Y.; data curation, J.H.; writing — original draft preparation, J.H.; writing — review and editing, J.H. and Y.D.; supervision, J.L., A.H., and X.W. All authors have read and agreed to the published version of the manuscript.

Funding: This research was funded by the National Key Research and Development Program of China (grant number 2016YFB0300500), the S\&T Innovation 2025 Major Special Program (Grant No. 2018B10031 and 2019B10090), the National Natural Science Foundation of China (Grant No. U1809216), and Major Science and Technology Project of Fenghua district of Ningbo (20194FHQ010015).

Conflicts of Interest: The authors declare no conflict of interest. 


\section{References}

1. Shokrollahi, H.; Janghorban, K. Soft magnetic composite materials (SMCs). J. Mater. Process. Technol. 2007, 189, 1-12. [CrossRef]

2. Kim, Y.B.; Jang, D.H.; Seok, H.K.; Kim, K.Y. Fabrication of Fe-Si-B based amorphous powder cores by cold pressing and their magnetic properties. Mater. Sci. Eng. A. 2007, 449, 389-393. [CrossRef]

3. Wu, Y.Q.; Bitoh, T.; Hono, K.; Makino, A.; Inoue, A. Microstructure and properties of nanocrystalline Fe-Zr-Nb-B soft magnetic alloys with low magnetostriction. Acta Mater. 2001, 49, 4069-4077. [CrossRef]

4. Zhong, X.; Liu, Y.; Li, J.; Wang, Y. Structure and magnetic properties of FeSiAl-based soft magnetic composite with $\mathrm{AlN}$ and $\mathrm{Al}_{2} \mathrm{O}_{3}$ insulating layer prepared by selective nitridation and oxidation. J. Magn. Magn. Mater. 2012, 324, 2631-2636. [CrossRef]

5. Lauda, M.; Füzer, J.; Kollár, P.; Strečková, M.; Bureš, R.; Kováč, J.; Bat'ková, M.; Bat’ko, I. Magnetic properties and loss separation in FeSi/MnZnFe ${ }_{2} \mathrm{O}_{4}$ soft magnetic composites. J. Magn. Magn. Mater. 2016, 411, $12-17$. [CrossRef]

6. Fan, X.A.; Wu, Z.Y.; Li, G.Q.; Wang, J.; Xiang, Z.D.; Gan, Z.H. High resistivity and low core loss of intergranular insulated Fe-6.5 wt.\%Si/SiO 2 composite compacts. Mater. Des. 2016, 89, 1251-1258. [CrossRef]

7. Luo, Z.; Fan, X.a.; Hu, W.; Luo, F.; Wang, J.; Wu, Z.; Liu, X.; Li, G.; Li, Y. Formation mechanism and enhanced magnetic properties of $\mathrm{Fe}-\mathrm{Si} / \mathrm{Fe}_{2} \mathrm{SiO}_{4}$ soft magnetic composites transformed from $\mathrm{Fe}-6.5 \mathrm{wt} \% \mathrm{Si} / \alpha-\mathrm{Fe}_{2} \mathrm{O}_{3}$ core-shell composites. J. Alloys Compd. 2020, 817. [CrossRef]

8. Liu, D.; Liu, X.; Wang, J.; Mao, X.; Xu, X.; Fan, X.a. The influence of Fe nanoparticles on microstructure and magnetic properties of Fe-6.5 wt\%Si soft magnetic composites. J Alloys Compd. 2020, 835. [CrossRef]

9. Zhang, Y.; Dong, Y.; Zhou, B.; Chi, Q.; Chang, L.; Gong, M.; Huang, J.; Pan, Y.; He, A.; Li, J. Poly-para-xylylene enhanced Fe-based amorphous powder cores with improved soft magnetic properties via chemical vapor deposition. Mater. Des. 2020, 191, 108650. [CrossRef]

10. Zhou, B.; Dong, Y.; Liu, L.; Chang, L.; Bi, F.; Wang, X. Enhanced soft magnetic properties of the Fe-based amorphous powder cores with novel $\mathrm{TiO}_{2}$ insulation coating layer. J. Magn. Magn. Mater. 2019, 474, 1-8. [CrossRef]

11. Sun, H.; Zhang, L.; Chen, Y.; Chen, F.; Qu, X.; Xie, C.; Zhang, L. Magnetic properties of iron-based soft magnetic composites prepared by utilizing polyimide insulating layer. J. Magn. Magn. Mater. 2019, 486, 165287. [CrossRef]

12. Zhou, B.; Dong, Y.; Liu, L.; Chi, Q.; Zhang, Y.; Chang, L.; Bi, F.; Wang, X. The core-shell structured Fe-based amorphous magnetic powder cores with excellent magnetic properties. Adv. Powder Technol. 2019, 30, 1504-1512. [CrossRef]

13. Shokrollahi, H.; Janghorban, K. The effect of compaction parameters and particle size on magnetic properties of iron-based alloys used in soft magnetic composites. Mater. Sci. Eng. B. 2006, 134, 41-43. [CrossRef]

14. Wang, J.; Liu, X.; Mo, J.; Mao, X.; Fan, X.a.; Luo, Z. The influence of doping Ti on the microstructure and magnetic performances of Fe-6.5Si soft magnetic composites. J. Alloys. Compd. 2018, 766, 769-774. [CrossRef]

15. Wang, J.; Liu, X.; Lei, C.; Mao, X.; Liu, D.; Fan, X.a.; Luo, Z.; Luo, F. Core loss reduction for Fe-6.5 wti\%Si soft magnetic composites doped with Co element. J. Magn. Magn. Mater 2020, 502, 166553. [CrossRef]

16. Taghvaei, A.H.; Shokrollahi, H.; Ghaffari, M.; Janghorban, K. Influence of particle size and compaction pressure on the magnetic properties of iron-phenolic soft magnetic composites. J. Phys. Chem Solids. 2010, 71, 7-11. [CrossRef]

17. Zhang, Z.; Wu, P.; Han, S.J.; Tang, F.L.; Su, H.L.; Tong, X.C.; Zou, Z.Q.; Wu, Y.M.; Wu, Y.C.; Du, Y.W. Effects of Annealing Temperature and Compaction Pressure on Magnetic Properties of Fe-Si Powder Cores Fabricated by an Improved Bluing Method. J. Supercond. Novel Magn. 2017, 31, 1507-1513. [CrossRef]

18. Abshinova, M.A.; Lopatin, A.V.; Kazantseva, N.E.; Vilčáková, J.; Sáha, P. Correlation between the microstructure and the electromagnetic properties of carbonyl iron filled polymer composites. Compos. Part A. 2007, 38, 2471-2485. [CrossRef]

19. Jo Sunday, K.; Hanejko, F.G.; Taheri, M.L. Magnetic and microstructural properties of $\mathrm{Fe}_{3} \mathrm{O}_{4}$-coated Fe powder soft magnetic composites. J. Magn. Magn. Mater. 2017, 423, 164-170. [CrossRef]

20. Bai, R.; Zhu, Z.; Zhao, H.; Mao, S.; Zhong, Q. The percolation effect and optimization of soft magnetic properties of FeSiAl magnetic powder cores. J. Magn. Magn. Mater. 2017, 433, 285-291. [CrossRef] 
21. Liu, H.J.; Su, H.L.; Geng, W.B.; Sun, Z.G.; Song, T.T.; Tong, X.C.; Zou, Z.Q.; Wu, Y.C.; Du, Y.W. Effect of Particle Size Distribution on the Magnetic Properties of Fe-Si-Al Powder Core. J. Supercond Novel Magn. 2015, 29, 463-468. [CrossRef]

22. Taghvaei, A.H.; Shokrollahi, H.; Janghorban, K. Properties of iron-based soft magnetic composite with iron phosphate-silane insulation coating. J. Alloys Compd. 2009, 481, 681-686. [CrossRef]

23. Silveyra, J.M.; Ferrara, E.; Huber, D.L.; Monson, T.C. Soft magnetic materials for a sustainable and electrified world. Science 2018, 362, eaao0195. [CrossRef] [PubMed]

24. Hui, X.; He, K.Y.; Qiu, Y.Q.; Wang, Z.J.; Cheng, L.Z.; Dong, Y.D.; Xue, X.S. Investigation of the Magnetic Properties of $\mathrm{Fe}_{73.5} \mathrm{Cu}_{1} \mathrm{Nb}_{3} \mathrm{Si}_{13.5} \mathrm{~B}_{9}$ Nanocrystalline Dust Core. J. Funct. Mater. 2000, 1, 42-45.

25. Johnson, M.T.; Visser, E.G. A coherent model for the complex permeability in polycrystalline ferrites. IEEE Trans Magn. 1990, 26, 1987-1989. [CrossRef]

26. Zhang, Y.Z.; Jin, H.J.; SHI, Y. General Properties of Low-frequency Power Losses in Fe-based Nanocrystalline Soft Magnetic Alloys. J. Mater. Sci. Technol. 2000, 16, 37-44.

27. Yaghtin, M.; Taghvaei, A.H.; Hashemi, B.; Janghorban, K. Effect of heat treatment on magnetic properties of iron-based soft magnetic composites with $\mathrm{Al}_{2} \mathrm{O}_{3}$ insulation coating produced by sol-gel method. J. Alloys Compd. 2013, 581, 293-297. [CrossRef]

28. Yang, B.; Li, X.; Guo, R.; Yu, R. Oxidation fabrication and enhanced soft magnetic properties for core-shell $\mathrm{FeCo} / \mathrm{CoFe}_{2} \mathrm{O}_{4}$ micron-nano composites. Mater. Des. 2017, 121, 272-279. [CrossRef]

29. Taghvaei, A.H.; Shokrollahi, H.; Janghorban, K.; Abiri, H. Eddy current and total power loss separation in theiron-phosphate-polyepoxy soft magnetic composites. Mater. Des. 2009, 30, 3989-3995. [CrossRef]

30. Kollár, P.; Birčáková, Z.; Füzer, J.; Bureš, R.; Fáberová, M. Power loss separation in Fe-based composite materials. J. Magn. Magn. Mater. 2013, 327, 146-150. [CrossRef]

31. Shen, T.D.; Harms, U.; Schwarz, R.B. Bulk Fe-Based Metallic Glass with Extremely Soft Ferromagnetic Properties. J. Metastable Nanocryst. Mater. 2002, 13, 441-446. [CrossRef]

32. Zhou, M.M.; Han, Y.; Guan, W.W.; Han, S.J.; Meng, Q.S.; Xu, T.T.; Su, H.L.; Guo, X.; Zou, Z.Q.; Yang, F.Y.; et al. Magnetic properties and loss mechanism of Fe-6.5 wti\%Si powder core insulated with magnetic Mn-Zn ferrite nanoparticles. J. Magn. Magn. Mater. 2019, 482, 148-154. [CrossRef]

Publisher's Note: MDPI stays neutral with regard to jurisdictional claims in published maps and institutional affiliations.

(C) 2020 by the authors. Licensee MDPI, Basel, Switzerland. This article is an open access article distributed under the terms and conditions of the Creative Commons Attribution (CC BY) license (http://creativecommons.org/licenses/by/4.0/). 